\title{
Natural History of Patients with $X$-ray-negative Dyspepsia in General Practice
}

\author{
D. W. GREGORY, G. T. DAVIES, K. T. EVANS, J. RHODES
}

British Medical fournal, 1972, 4, 519-520

\section{Summary}

When 102 patients with dyspepsia who had normal findings on barium-meal examination in 1964 were interviewed in 1970,85 of them $(76 \%)$ were symptomatically improved, and only three were later shown to have a peptic ulcer. This suggests that " $x$-ray-negative dyspepsia" has a good prognosis in a general practice setting.

\section{Introduction}

Many patients who are referred for a barium-meal examination with symptoms of peptic ulcer have normal radiological findings. They have been referred to as patients with "pseudoulcer" or " $x$-ray-negative dyspepsia." There is little information about the long-term follow-up of such patients (Lipetz et al, 1955; Barfred, 1959; Brummer, and Hakkinen, 1959; Krag, 1965), and all but one of these reports were confined to those attending hospital. We wondered whether the prognosis of a group of patients who had normal findings on barium-meal examination would be any different in a group referred by general practitioners and subsequently treated by them. Consequently, we reviewed such patients who had attended the general-practitioner $x$-ray unit in Cardiff six years previously.

\section{Methods and Results}

On reviewing 276 barium-meal examinations carried out in 1964,102 findings were regarded as normal by two radiologists (G.T.D. and K.T.E.). The original radiological diagnosis was then compared with the review diagnosis. Nine of the examinations had previously been recorded as showing a duodenal ulcer, producing an inter-observer error of $3.6 \%$. Subsequently the patients were visited at home, and a questionnaire relating to symptoms that were present in 1964 was completed. This included the length of history, the relation of symptoms to food, and whether alkali gave relief. The severity of subsequent and current symptoms was noted. Progression or improvement in symptoms was assessed by relating the symptoms in 1964 with those in the three months preceding the interview. It was also determined whether the symptoms had improved, remained the same, or worsened. A record was made of any later investigation of the gastrointestinal tract with details of admission to hospital for surgical or medical treatment. Information about patients who had died was obtained from the general practitioner, hospital records, or death certificates. The hospital records of those admitted during the follow-up period were examined and compared with details given at the interview. Further investigations were carried out on patients who complained of a deterioration in symptoms.

Complete questionnaires were obtained from 85 of the 102

Welsh National School of Medicine, Cardiff

D. W. GREGORY, M.B., M.R.C.P., Registrar in Diagnostic Radiology

G. T. DAVIES, M.R.C.P., F.F.R., Consultant Radiologist

K. T. EVANS, F.R.C.P., F.F.R., Professor of Radiology

J. RHODES, M.D., M.R.C.P., Consultant Physician

patients selected, a response rate of $83 \%$. Six patients had died and the remaining 11 could not be traced. The male to female ratio for the group was $1 \cdot 6$, showing a male preponderence. The ages of the patients at the time of the original examination are shown in Fig. 1.

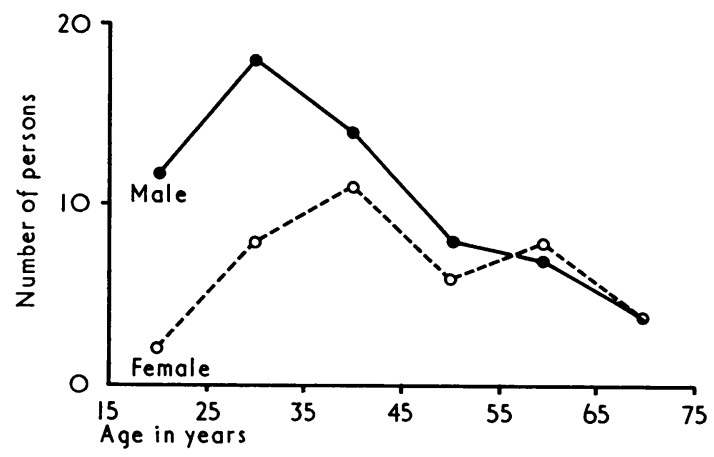

FIG. 1-Age distribution of study group in 1964 .

\section{SYMPTOMS}

The length of history before the 1964 barium-meal examination was less than one year in $54 \%$ and less than three years in $72 \%$ of the patients (Fig. 2). Three patients who were later shown to have a peptic ulcer had experienced symptoms for more than three years at the time of the first barium meal. With the exception of one patient with dysphagia all had been originally referred for radiological examination because of dyspepsia, and in $80 \%$ the symptoms were related to food and there was relief after taking alkali.

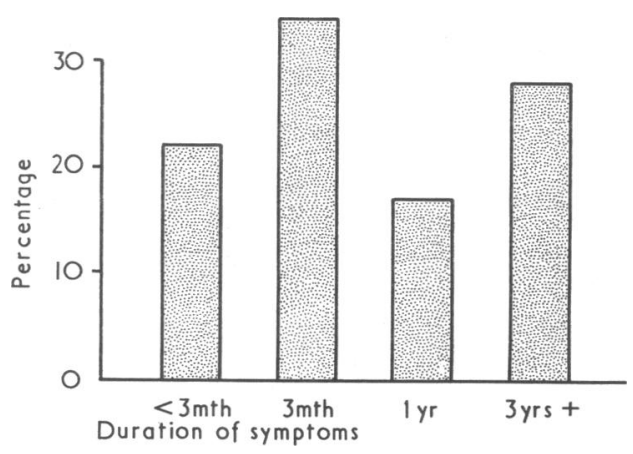

FIG. 2-Duration of symptoms before 1964.

\section{MANAGEMENT AND PROGRESS}

Since 1964 most patients' symptoms had improved; 65 stated there had been definite improvement, 15 claimed there had been no change, and five had subsequently deteriorated. The five patients whose symptoms had become worse were reinvestigated at the time of follow-up. One was shown to have gall stones and another had a hiatus hernia. Repeat radiological studies on the remaining three patients again showed no evidence of peptic ulceration.

Of the remaining 80 patients, eight had been referred to hospital for further investigation during the follow-up period. Further barium-meal examinations had shown that one patient 
had developed a duodenal ulcer, one a gastric ulcer, one a combined duodenal and gastric ulcer, and one was found to have radiological evidence of achalasia of the cardia. These patients were referred for surgical treatment, with excellent results in all except the patient with achalasia. Of the four remaining patients, further radiological investigation had shown renal disease in two, but with no evidence of gastrointestinal disease, and two were again found to have no abnormality.

When the radiological diagnosis for the 1964 barium-meal study was compared with the follow-up diagnosis six years later it changed in eight cases. Six, as indicated above, developed upper gastrointestinal lesions, and two were found to have renal disease. None of these patients experienced gastrointestinal haemorrhage or perforation during the period of follow-up. Six had died, but in none was the recorded cause of death attributable to a lesion in the upper gastrointestinal tract.

\section{Discussion}

An increasing number of patients with dyspepsia are referred for radiological investigations by their general practitioners because a peptic ulcer is suspected. In this series few (3.5\%) of those patients with a normal finding on barium-meal examination in 1964 were later found to have a peptic ulcer. Most showed appreciable symptomatic improvement, 65 (76\%) claiming to have little or no dyspepsia when questioned in 1970. Fifteen patients claimed there had been no change in their symptoms. The five patients shown by the questionnaire to have deteriorated symptomatically were reinvestigated, and in two a positive diagnosis was obtained.

Similar groups of patients studied over an extended period have shown a much higher incidence of peptic ulceration in follow-up. In a group of 174 hospital patients who were followed for 27 years, $40 \%$ were shown to have a peptic ulcer at subsequent investigations (Krag, 1965). Brummer and Hakkinen (1959) followed 102 patients over a six-year period and found that 12 had developed a peptic ulcer. Barfred (1959) followed 235 patients over a 10-year period, and $30 \%$ developed a peptic ulcer during this time.

The lower incidence of peptic ulcer in our study may be related to two factors. Firstly, all of the present patients were referred directly from general practitioners, whereas the reports referred to above all dealt with a hospital population. Secondly, a longer follow-up period would possibly have given a higher incidence of the subsequent development of peptic ulceration. We believe that this would be unlikely as $76 \%$ of the present patients were virtually symptomless six years later.

If we assume that " $x$-ray-negative dyspepsia" represents a separate disease entity then its prognosis is more favourable than for peptic ulcer, most patients showing appreciable improvement with time. If further investigations are reserved only for those patients who show a deterioration symptomatically then the burden of repeated reinvestigations both for the radiological services and the patients will be eased, so reducing unnecessary investigations.

We would like to thank Professor H. Campbell, of the department of medical statistics, for advice in the planning of this study, and also Mrs. R. Moss for secretarial help.

\section{References}

Barfred, A. (1959). Proceedings of the World Congress on Gastroenterology, p. 352. Baltimore, Williams and Wilkins.

Brummer, P., and Hakkinen, I. (1959). Acta Medica Scandinavica, 165, 329.

Krag, E. (1965). Acta Medica Scandinavica, 178, 713

Lipetz, S., Sklaroff, S. A., and Stein, L. (1955). British Medical fournal, 2, 172 .

\title{
Viral Infection and Renal Transplant Rejection
}

\author{
J. D. BRIGGS, MORAG C. TIMBURY, A. M. PATON, P. R. F. BELL
}

British Medical fournal, 1972, 4, 520-522

\section{Summary}

The occurrence of an outbreak of influenza in a renal transplant unit is described. Five patients had a proved episode of infection, confirmed by a rise in the complement fixation titre to influenza virus $A$, and this coincided in three of the patients with episodes of acute rejection. It seems likely that the virus infection was responsible for the rejection, possibly through a stimulating effect of the virus on the host's immune response.

\section{Introduction}

Rejection remains the most common and important complication of renal transplantation. In some cases factors which pre-

Renal Unit, Western Infirmary, Glasgow

J. D. BRIGGS, M.B., M.R.C.P., Consultant Physician

A. M. PATON, M.B., M.R.C.P., Medical Registrar

Institute of Virology, University of Glasgow

MORAG C. TIMBURY, M.D., M.R.C.PATH., Senior Lecturer

University Department of Surgery, Western Infirmary, Glasgow P. R. F. BELL, M.D., F.R.C.S., Consultant Surgeon cipitate the rejection can be defined, such as a reduction in dosage of immunosuppressive drugs. In most patients, however, rejection episodes occur without warning and in the absence of obvious precipitating factors. Rarely, an association has been noted between viral infection and rejection (Simmons et al., 1970; David et al. 1972). This paper describes the occurrence of a localized outbreak of influenza associated with acute rejection.

\section{Outbreak}

In the winter of 1971-2 there was an epidemic of influenza due to $\mathrm{Al} /$ Hong Kong/68 virus in the West of Scotland. In January and February 1972 a localized outbreak of influenza occurred in the renal transplant unit of the Western Infirmary, Glasgow, which affected five patients with renal transplants and one patient on regular haemodialysis. The main features of the outbreak in the patients with transplants are summarized in the Table. Details of the clinical history of each patient are given below.

Case 1.-A 20-year-old man with membranous glomerulonephritis received a cadaver kidney on 30 Ocober 1971. Tissue typing showed HL-A antigens 2, 10, and 12 in both the donor and recipient, with one unidentified antigen at the second sublocus. 